\title{
Temporal variations in the primary energy use and greenhouse gas emissions of electricity provided by the Swiss grid
}

\author{
Didier Vuarnoz*, Thomas Jusselme \\ Building 2050 Research Group, Ecole Polytechnique Fédérale de Lausanne (EPFL), Passage du Cardinal 13B, CH-1700 Fribourg, Switzerland
}

\section{A R T I C L E I N F O}

\section{Article history:}

Received 12 March 2018

Received in revised form 7 July 2018

Accepted 14 July 2018

Available online 24 July 2018

\section{Keywords:}

Swiss electricity mix

Hourly conversion factor

Greenhouse gas emissions

Cumulative energy demand

Non-renewable cumulative energy demand

Emission factor

\begin{abstract}
A B S T R A C T
It is a frequent practice nowadays to use mean annual conversion factors (CFs) when performing lifecycle assessment (LCA) of processes and products that use electricity supplied by the grid. In this paper, we conduct an hourly assessment of the greenhouse gas (GHG) emission factor, along with the conversion factors for the cumulative energy demand (CED) and its non-renewable part (CEDnr), of electricity supplied by the Swiss grid and its direct neighboring countries (France, Germany, and Austria; Italy being neglected). Based on an hourly inventory of energy flows during a one-year period (2015 -2016), this attributional approach allows performance of various certification procedures of process or product manufacturing, and comparison of energy and carbon intensities of different national mixes. Hourly calculation allows evaluation of the order of magnitude of errors made when considering an annual mix. Visualization techniques are used to better understand the obtained data and to detect when strategies involving timing optimization of electricity use may be efficient. A case study is chosen to illustrate the relevance of hourly CFs when performing LCA associated to the exploitation of a given building. Moreover, mean annual CFs of interest are discriminated by electricity end-use sectors. This could be of great help for system designers willing to improve the assessment accuracy when hourly $C F s$ are not readily available.
\end{abstract}

() 2018 Elsevier Ltd. All rights reserved.

\section{Introduction}

Life-cycle impacts of electricity depend mainly on the production process. At a national level, electricity is either produced domestically or imported from surrounding countries, and generated by various production technologies that induce different environmental impacts. The share of the technologies used to generate electricity varies continuously, due to energy resource availability and in order to adapt the power supply to an everchanging demand. Therefore, each kWh at the consumer's disposal does not have the same environmental impact over time. However, the specific nature of the alternating current does not allow a physical tracking of electrons from a given power plant to the final consumer, and therefore an environmental labelling of each kWh remains conceptual. Through life-cycle electricity generation inventories, the correct understanding regarding the origin and responsibility level of each contributor is a fundamental key that grid managers and policymakers could use for efficient energy

\footnotetext{
* Corresponding author.

E-mail address: didier.vuarnoz@epfl.ch (D. Vuarnoz).
}

transition toward the decarbonization of electricity (see Ref. [1-3]).

This study deals with a limited selection of environmental impact categories, with the aim of providing to engineers and practitioners the necessary input data to various assessments of processes and products using electricity; this is particularly needed in the construction sector for certification procedures (e.g. Ref. $[4,5])$ and for sustainability assessments needed for quality label, such as LEED [6], HQE [7], or BREEAM [8]. Therefore, the scope of the study focuses on the hourly assessment of the greenhouse gas (GHG) emission factor, along with the conversion factors for the cumulative energy demand (CED) indicator and its non-renewable part $\left(C D_{n r}\right)$, associated with the electricity supplied by a given national grid. These factors-respectively $C F_{G H G}, C F_{C E D}$, and $\mathrm{CF}_{\text {CEDnr }}$-are important when assessing GHG emissions, as well as energy use efficiency and the amount of energy from sources that may be depleted by extraction, when using an electric grid as power supply. These factors consider the whole life-cycle (cradle-tograve boundary, see Ref. [9] of a mean representative unit of electricity supplying a national grid at a given time. The GHG emission factor $C_{G H G}$-also called simply emission factor [10], $\mathrm{CO}_{2 \text {-eq }}$ footprint [11], or carbon footprint [12] in the current literature-is 
expressed in $\left[\mathrm{kg} \mathrm{CO} \mathrm{CO}_{2 \text {-eq }} \mathrm{kWh}^{-1}\right]$. Both $C F_{C E D}$ and $C F_{C E D n r}$ are expressed in [MJ oil-eq $\mathrm{kWh}^{-1}$ ]. Choosing a functional unit of $1 \mathrm{kWh}$ of electricity production mix at extra-high voltage $(380 \mathrm{kV}$ or $220 \mathrm{kV}$ ), and integrating transport and distribution losses enable comparison with other national grids.

Two assessment methods can determine time-dependent conversion factors of electricity mix. Ex post data, with an attributional approach ([13] for France; [11] for Belgium) are used when the objective is to depict the potential impacts of using a given national grid (e.g. certification procedure). By knowing the dynamic patterns and the variation amplitudes of the conversion factors assessed within an attributional approach, this knowledge can inform when timing optimization of electricity use could be applied for energy and/or GHG emission mitigation [14]. However, when the goal is to evaluate the impacts of a certain change in a system (for example, in the electricity generation mix), the potential of mitigation occurring with this change is assessed with a marginal approach, which is compulsory in consequential studies (See [15] for France; [16] for Sweden, [10] for Finland). The applicability of both the attributional and consequential approaches is discussed in more detail in Soimakallio et al. [17]. In the present study, CFs are evaluated on the base of a time-resolved attributional LCA, with hourly averaged energy produced per each generation technology.

In current life-cycle impact assessment, it is common to use yearly averaged conversion factors of a national electricity mix (e.g. Ref. [18]). In this study, yearly averaged conversion factors are referred to as the "conventional method". The lack of temporal resolution generates inaccuracies in assessments, especially when the electricity consumption and the conversion factors of the grid are highly variable over time (see Refs. $[19,13,14]$ ). This is problematic, notably in buildings where operational performances are under the scope of norms, standards, and various certifications (e.g. Ref. $[4,5])$. Temporal variability needs to be included in the environmental footprints of electricity for various reasons. Hourly conversion factors allow not only more accurate energy and emission assessments to be guaranteed even when the electricity demand varies over time, but also to detect when a timing optimization of electricity use may be efficiently deployed (see Refs. $[10,14]$ ). These kind of strategies can be neither assessed nor deployed with a yearly-averaged CFs of a given national grid. Another benefit of introducing hourly conversion factors is related to the massive introduction of decentralized electricity generation and building energy storage, which enable managing a shift between production and consumption. Consequently, the challenge is no longer to fulfill a given amount of harvested and stored energy, but to understand the life-cycle qualities of this renewable energy, which should ideally be better than those of the grid mix. A last example is given in the context of the constant decay in building energy consumptions. As a consequence, the relative accuracy of life-cycle assessments significantly decrease if more robust impact assessments techniques are not introduced.

The Swiss grid is very interesting considering its high share of exchanges with neighboring countries, and it is considered as the main subject of interest of this study. In Switzerland, the CED, the CEDnr, and the GHG emissions are highly important, since they have been selected as the main indicators of the 2000W society vision [20]. Hourly conversion factors related to these three indicators are not yet available for the Swiss mix. In this paper, we first present the methodology and discuss the data availability for Switzerland as well as for its surrounding countries. We then present the obtained results, consisting of the hourly conversion factors $C F_{G H G}^{h} C F_{C E D}^{h}$, and $C F_{C E D n r}^{h}$ for the Swiss, Austrian, French, and German grids. In the second part of the study, the traditional method of energy and emission assessment (dealing with mean annual conversion factors) is compared with a method using hourly conversion factors, using a case study consisting of a highlyefficient building in central Switzerland that represents future construction trends. Furthermore, we address the relevance of conversion factors discriminated by end-use sectors of electricity in the building taken as the case study. The expected audience of this study is composed of LCA practitioners, energy engineers and researchers, and electric grid managers and policymakers.

\section{Methodology}

The LCA methodology used in this study to assess the Swiss grid follows the ISO 14040/14044 guidelines [21,22] and the ILCD handbook [12]. We consider a spatially-homogeneous quality of electricity in a given country. When considering the electricity delivered to the national grid of a country $c$, given a category indicator $m$ in a time interval $i$, the assessment of an impact score $I S_{c, m, i}$ is obtained as follows:

$I S_{c, m, i}=I S_{c, m, i}^{D P}+I S_{m, i}^{I}-I S_{c, m, i}^{E}$

where $I S_{c, m, i}^{D P}$ is the impact score of domestic production; $I S_{m, i}^{I}$ is the impact score resulting from the imports of electricity from surrounding countries; and $I S_{c, m, i}^{E}$ is the impact score related to electricity exports. They are evaluated in the present study, respectively, in the following manner (Eqs. (2)-(4)):

$I S_{c, m, i}^{D P}=\sum_{f} G E_{c, f, i} \cdot C F_{m, f}$

with $G E_{c, f, i}$ being the net generated electricity by technology type $f$, and $C F_{m, f}$ being the technology-specific conversion factor of a given category indicator $m$.

$I S_{m, i}^{I}=\sum_{n} E_{n, i}^{I} \cdot C F_{m, n, i}$

with $E_{n, i}^{I}$ being the imported electricity from a neighboring country $n$, and $C F_{m, n, i}^{E}$ being the country-specific conversion factor of a given category $m$.

$I S_{c, m, i}^{E}=E_{c, i}^{E} \cdot C F_{c, m, i}$

with $E_{c, i}^{E}$ being the sum of exported electricity from the exporting country $c$ to its surrounding countries, and $C F_{c, m, i}$ being the national conversion factor of a given impact category $m$ :

$C F_{c, m, i}=\frac{I S_{c, m, i}^{D P}+I S_{m, i}^{I}}{\sum_{f} G E_{c, f, i}+\sum_{n} E_{n, i}^{I}}$

When applying this description to a region of interest, a domino-chain reaction occurs in the sense that a surrounding country $n$ subsequently becomes a country of main interest $c$. In other words, each grid (with its own set of conversion factors) is influenced by the features of the surrounding grids from which electricity is imported. In this study, we limit the data inventory by introducing a simplification concerning electricity imports from surrounding countries $n$. Instead of Eq. (3), we consider the share of imports in the national grids surrounding $c$ to be time-independent and with conversion factors equivalent to those of the European Network of Transmission System Operators for Electricity (ENTSOE) mix supply. Therefore, Eq. (5) applied to a surrounding country $c$ becomes: 
$C F_{m, n, i}=\frac{I S_{m, n, i}^{D P}+I S_{m, n, i}^{I}}{\sum_{f} G E_{c, f, i}+\sum_{n} E_{n, i}^{I}}$

where

$I S_{m, n, i}^{I}=E_{n, i}^{I} \cdot C F_{m, E N T S O-E}$

With $E_{n, i}^{I}$ being the sum of the electricity imported to country $c$, and $C F_{m, E N T S O-E}$ being the mean annual conversion factor of the ENTSO-E mix supply. By such simplification, we introduce a second range of accuracy in the model; the highest level of accuracy in the conversion factors is obtained for the main country of interest $c$, and the lower-range level concerns the surrounding countries $n$.

In this study, the methodology could be used for any environmental indicators, but the chosen safeguard subjects are limited to the impact category of climate change and the depletion of fossil resources. Their respective indicators are the GHG emission factor and the conversion factor for the cumulative energy demand (CED). Furthermore, we distinguish the part of the energy requirement provided by non-renewable resource (CEDnr). These indicators are assessed along their entire life-cycle on a cradle-to-grave framework (extraction of resources, manufacturing, use, and final disposal of products). The CED is based on an energy-harvested approach and on higher heating values, and are provided by the КВOB database [23]. Allocation based on exergy is applied for the cogeneration process. Because CED is rather abstract for the nonspecialist, in some data representation proposed in this study we have converted its value into the primary energy factor $(P E F)$, describing how much primary energy is necessary to process one unit of electricity. In addition, the non-renewable ratio $r_{n r}=C F_{\text {CEDnrl }}$ $C F_{C E D}$ is proposed for displaying the data more straightforwardly than with absolute value. Exponents $h$ and $y$, hourly and yearly respectively, are used to make the nature of the assessment more precise. The technology-related emission factors used in this study are provided by the KBOB database [23], and comprise transport and distribution losses. They have been calculated on the base of life-cycle inventory data of the ecoinvent 2.2 + database [24], with the 100-year global warming potential model provided by the Intergovernmental Panel on Climate Change (IPCC) [25].

\section{Data collection}

We apply this methodology to Switzerland as the country of main interest $c$, where hourly conversion factors were not yet available. We take into consideration the electricity supplied to the Swiss grid. Surrounding countries-France, Germany, and Austria (see Fig. 1)-are also assessed, but with a lower level of accuracy due to the simplification stated in Eq. (7). Italy is disregarded in the present study, as it delivers virtually no electricity to Switzerland (2.4\% of the Swiss imports during the considered period). The electricity generation inventory includes hourly electricity flows and technology-specific conversion factors of the different contributors to electric grids belonging to Switzerland and to those of the direct surrounding countries. The period of the assessment is one year, from January 28, 2015, until January 27, 2016, during which the LCA is temporally resolved at the hourly time step.

Extensive data collection of hourly domestic production that supplies a given national grid is presently very challenging. In Switzerland, for instance, the electricity supplied to end users is provided by approximately 700 companies [26]. We collected realworld data related to domestic productions of Switzerland, Germany, and Austria at the leading energy exchanges in Central Europe EEX [27]. Although EEX does not trade the full amount of a

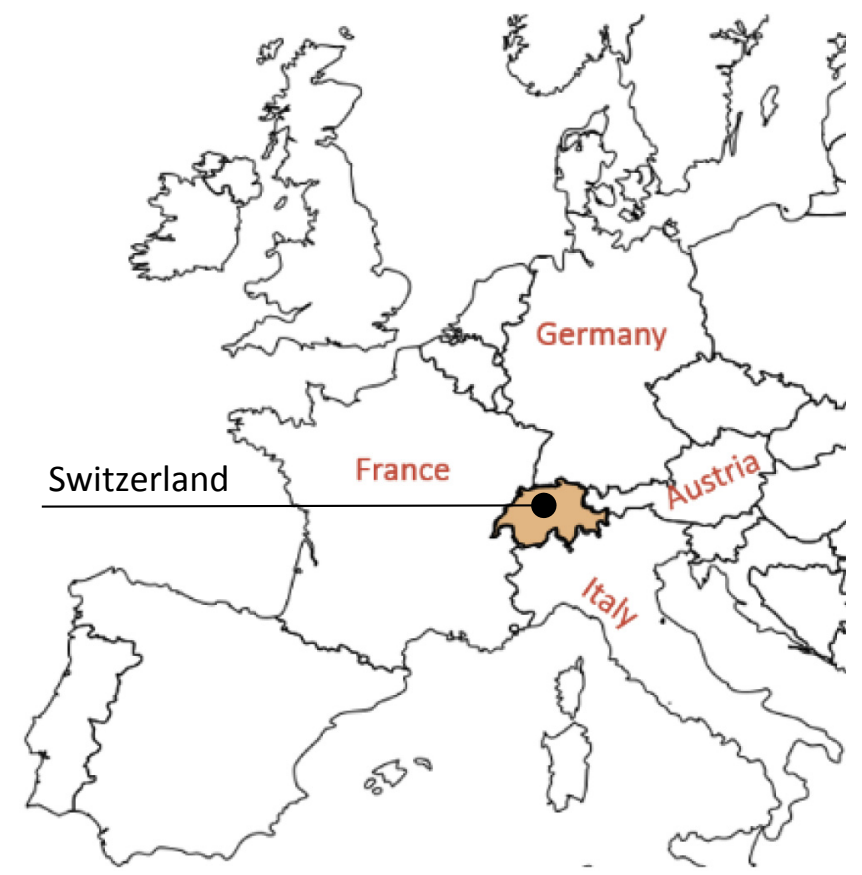

Fig. 1. Geographic scope of the study, with Switzerland as the country of main interest and its surrounding countries.

domestic production, their data is currently the best available source of information. For example, $43 \%$ of the electricity produced in Switzerland was traded by EEX during the period taken into consideration in this study. An estimate of missing contributors is possible by crossing data collected from EEX with those coming from other sources of information [18]. On that basis, the technologies missing from the inventory are evaluated as follows: for Austria, garbage ( $0.8 \%$ of the mix), oil ( $1.3 \%)$, solar $(0.03 \%)$, and wind (2.4\%); for Switzerland, waste (1.6\%), bio-energy $(0.2 \%)$, and solar $(0.02 \%)$. The small quantities and the kinds of different missing electricity contributions indicate that for these countries (Switzerland and Austria), the loss of information should concern mainly small-sized renewable power generation units that are devoted to local consumption. For France, the hourly data of the different technology-specific domestic production is given by RTE [28], the sole manager of the French grid. The only missing contribution in comparison with Itten et al. [18] concerns municipal waste $(0.6 \%)$. Thus, the robustness of the data for this country is considered to be very high. No apparent missing contribution is noticed for Germany.

The electricity generation inventory of domestic production tells us that even though the countries investigated in this article are geographically very close, each national grid is supplied by a very different supply mix than the ones of its neighbors. Fig. 2 presents an overview of the technologies and imports involved in the supply of the different considered national grids. The Swiss grid is mainly generated by hydro and nuclear at almost equal shares, and is fed by a significant share of imported electricity from surrounding countries (about one-third). In these surrounding countries, the share of foreign electricity varies from very low values (2\% in France) to amounts that are comparable but always smaller to Switzerland's electricity imports. For the national electric grids surrounding Switzerland, some general features can be addressed. Austria's electricity relies mainly on low-carbon hydro. Two-thirds of German electricity is provided by carbon-intensive fossil fuels. The French grid relies mostly on nuclear-pressurized water reactors 


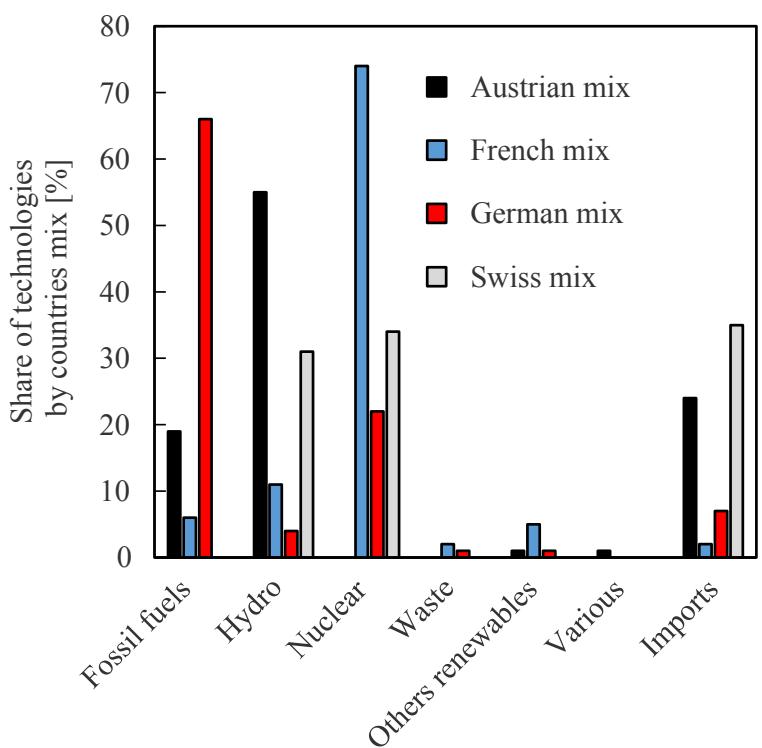

Fig. 2. The share of the electricity's origin for the Austrian, French, German, and Swiss mixes. (See Table 1 for the source of data).

(three-quarters). For these countries surrounding Switzerland, shares in technology production are consistent with those of Itten et al. [18].

Two types of data are considered with regards to national electricity imports and exports. For Switzerland, time-dependent flows of electricity imports from directly-neighboring countries are taken into account. These are provided with a 15-min time step by the Swiss transmission grid operator Swissgrid [29]. The conversion factors resulting from these imports are also considered to be time-dependent and are evaluated by Eq. (6). For countries surrounding Switzerland, the energy shares of annual imports are provided by Itten et al. [18] and are distributed equally throughout the year. The time-independent conversion factor related to these imports is chosen to be the one of the ENTSO-E mix supply (KBOB database from Ref. [23]. Table 1 summarizes the different sources of data used in the present study.

\section{Results}

Based on the methodology and the electricity-generation inventory presented in the previous section, we obtained the hourly conversion factors $C F_{G H G}^{h}, C F_{C E D}^{h}$, and $C F_{C E D n r}^{h}$ for the Swiss mix and its surrounding countries during a one-year period. This section aims to explore these obtained data. The corresponding dataset of the Swiss mix is available in the additional information of the paper. $C F_{G H G}$ is plotted in Fig. 3 (lower curve) with the time reference GMT +1 . In order to convey the meaning of these results in an intelligible representation, we transformed $C F^{h}{ }_{C E D}$ into primary energy factor $P E F=C F_{C E D}^{h} / 3.6 \mathrm{MJ} \mathrm{kWh}^{-1}$ (center curve) and $C F_{C E D n r}^{h}$ into $r_{n r}=C F_{C E D n r}^{h} / C F_{C E D}^{h}$ (upper curve). No filter has been applied to smooth curves. The results clearly indicate that the PEF follows the same evolving trends of the non-renewable ratio $r_{n r}$. Both GHG emissions and energy conversion factors are at their lowest during summertime, when availability of renewable energy is high.

Summative statistics of the hourly GHG emission factor, as well as for conversion factor for the cumulative energy demand and its non-renewable part, are presented in Tables $2-4$, respectively. In these tables, a mean annual value $\mu^{y}$ and a coefficient of variation

Table 2

Summary of emission factors $C F_{G H G}^{h}$ obtained for Switzerland and its surrounding countries during a one-year period.

\begin{tabular}{llllll}
\hline \multirow{2}{*}{ Country } & \multicolumn{2}{l}{$C F_{G H G}$} & & Contributors \\
\cline { 2 - 3 } \cline { 5 - 6 } \cline { 5 - 6 } & $\mu^{y}\left[\mathrm{~kg} \mathrm{CO}_{2 \mathrm{eq}} \mathrm{kWh}^{-1}\right]$ & $C V^{y}[-]$ & & $\mu_{c}^{y}\left[\mathrm{~kg} \mathrm{CO}_{2 \mathrm{eq}} \mathrm{kWh}^{-1}\right]$ & $C V_{c}^{y}[-]$ \\
\hline Austria & 0.349 & 0.222 & & 0.026 & 0.582 \\
Germany & 0.851 & 0.078 & & 0.145 & 0.542 \\
France & 0.078 & 0.306 & & 0.008 & 0.502 \\
Swiss DP & 0.040 & 0.389 & & 0.027 & 0.519 \\
Swiss mix & 0.206 & 0.410 & & N/A & N/A \\
\hline
\end{tabular}

Table 1

Overview of the different sources of data used in the present study.

\begin{tabular}{|c|c|c|c|}
\hline Countries & Imported energy & Imports: conversion factors & Domestic production (DP): share of technologies \\
\hline Switzerland & Swissgrid [26] & Present study & EEX [24] \\
\hline Austria & Itten et al. [16] & ENTSO-E [21] & EEX [24] \\
\hline Germany & Itten et al. [16] & ENTSO-E [21] & EEX [24] \\
\hline France & Itten et al. [16] & ENTSO-E [21] & RTE [25] \\
\hline
\end{tabular}

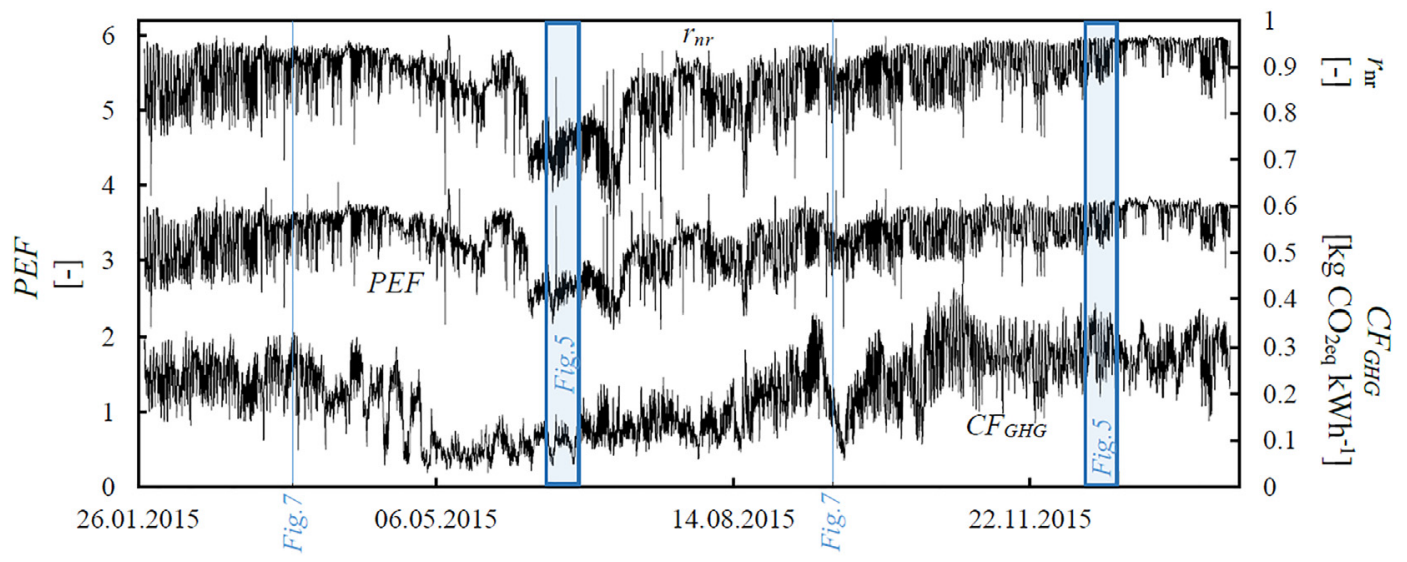

Fig. 3. Hourly variation of the primary energy factor $(P E F)$, the non-renewable ratio $\left(r_{n r}\right)$, and the GHG emission factor $\left(C F_{G H G}\right)$ of the electricity mix feeding the Swiss grid. 
Table 3

Summary of statistics based on hourly cumulative energy demand (CED) conversion factors $C F^{h}{ }_{C E D}$ obtained for Switzerland and its surrounding countries during a oneyear period.

\begin{tabular}{|c|c|c|c|c|}
\hline \multirow[t]{2}{*}{ Country } & \multicolumn{2}{|l|}{$C F_{C E D}$} & \multicolumn{2}{|l|}{ Contributors } \\
\hline & $\mu^{y}\left[\mathrm{M}_{\text {oil-eq }} \mathrm{kWh}^{-1}\right]$ & $C V^{y}[-]$ & $\mu_{c}{ }^{y}\left[\mathrm{MJ}_{\text {oil-eq }} \mathrm{kWh}^{-1}\right]$ & $C V_{c}^{y}[-]$ \\
\hline Austria & 12.046 & 0.046 & 0.860 & 0.514 \\
\hline Germany & 13.615 & 0.014 & 2.316 & 0.545 \\
\hline France & 12.958 & 0.037 & 1.356 & 0.419 \\
\hline Swiss DP & 11.412 & 0.149 & 7.327 & 0.191 \\
\hline Swiss mix & 11.859 & 0.109 & $\mathrm{~N} / \mathrm{A}$ & $\mathrm{N} / \mathrm{A}$ \\
\hline
\end{tabular}

Table 4

Summary of statistics based on hourly non-renewable cumulative energy demand (CEDnr) characterization factors $C F^{h}{ }_{C E D n r}$ obtained for Switzerland and its surrounding countries during a one-year period.

\begin{tabular}{|c|c|c|c|c|}
\hline \multirow[t]{2}{*}{ Country } & \multicolumn{2}{|l|}{$C F_{\text {CEDnr }}$} & \multicolumn{2}{|l|}{ Contributors } \\
\hline & $\mu^{y}\left[\mathrm{MJ}_{\text {oil-eq }} \mathrm{kWh}^{-1}\right]$ & $C V^{y}[-]$ & $\mu_{c}{ }^{y}\left[\mathrm{MJ}_{\text {oil-eq }} \mathrm{kWh}^{-1}\right]$ & $C V_{c}^{y}[-]$ \\
\hline Austria & 10.446 & 0.041 & 0.750 & 0.517 \\
\hline Germany & 13.343 & 0.017 & 2.270 & 0.545 \\
\hline France & 12.287 & 0.051 & 1.289 & 0.425 \\
\hline Swiss DP & 9.7017 & 0.246 & 6.149 & 0.236 \\
\hline Swiss mix & 10.458 & 0.181 & $\mathrm{~N} / \mathrm{A}$ & $\mathrm{N} / \mathrm{A}$ \\
\hline
\end{tabular}

$C V^{y}$ (defined as the ratio of the standard deviation $\sigma^{y}$ to the mean value $\mu^{y}$ ) are reported not only for the Swiss grid and its own domestic production (DP), but also for the grids belonging to the countries directly surrounding Switzerland. $C V^{y}$ is used to indicate the risk for inaccuracies in the impact assessment with mean annual conversion factor. Using $C V^{y}$ rather than $\sigma^{y}$ offers the possibility to directly compare the different variation levels exhibited by each national mix. In the same tables (Tables $2-4$ ), $\mu_{c}^{y}$ stands for the mean absolute contribution from each of the surrounding countries to the Swiss conversion factors of concern. The variability of these contributions throughout the year is expressed by a coefficient of variation $C V_{c}{ }^{y}$.

Tables 2-4 allows for comparison of the different mean annual values of the conversion factors obtained from the hourly assessment for the national grids within the scope of this study. For the three investigated indicators and their respective conversion factors, electricity provided by the Swiss domestic production is always less intensive both in term of energy use and GHG emissions. On the same basis, electricity supplied by the German grid exhibits the worst values. Its electricity is generated by technologies that need $16 \%$ more cumulative energy ( $27 \%$ more for the $C_{E D}$ ) than the Swiss domestic production. The most striking disparity between the obtained national conversion factors is that of the GHG emissions. Throughout the year taken into consideration, only $17 \%$ of the electricity supplied to the Swiss grid is provided by Germany (see left side of Fig. 4). However, these imports are responsible for $70 \%$ of the GHG emissions of the Swiss mix (see right side of Fig. 4).

The fluctuation of the hourly conversion factors with $C V^{y}$ allows us to observe that the German grid has the most stable conversionfactors results over time. This indicates that relatively small imprecisions are induced when using mean annual conversion factors for the German grid for performing LCA. Conversely, large variations in the different hourly conversion factors of the Swiss grid indicate that substantial inaccuracies in energy and emission assessments may occur when using the conventional method. At the same time, and especially due to this relatively large variation, Switzerland appears to be the most suitable country to possibly implement strategies involving timing optimization of electricity use for GHG emissions and energy-use mitigation.

It is possible to decompose a given environmental footprint according to the different sources of electricity. In Fig. 5, the different contributions of the Swiss mix (domestic and imported electricity) and their respective share of responsibilities are disclosed for $C F^{h}{ }_{C E D}$ (upper part), $C F^{h}{ }_{C E D n r}$ (center part), and $C F_{G H G}^{h}$ (lower part) for two periods of 10 days during the summer (left part) and the winter (right part) periods. These two time lapses are also reported by two blue rectangles in Fig. 3 .

According to Fig. 5 and from the Swiss grid point of view, the major contributor to both the CED and CEDnr conversion factors during summer is the Swiss domestic production. In terms of absolute values, this domestic contribution-as well as the French one-do not evolve very much toward winter. The contribution of Austrian imports on $C F_{G H G}, C F_{C E D}$, and $C F_{C E D n r}$ becomes slightly more important from summer to winter, and much more important for the German imports. Over the year, the highest cumulative energy demand and emission factors associated with the Swiss grid are during the winter, due to the massive increase of German imports.

All the differences obtained in the conversion factors depicting the different national grids originate from the different share of technology processes used to generate electricity. In Fig. 6, where the primary energy factor $(P E F)$ and the GHG emission factor $C F_{G H G}$ are respectively drawn in the $\mathrm{x}$-axis and the $\mathrm{y}$-axis, black triangles indicate the technology-specific characteristic values from the KBOB database (from Ref. [21], as well as some given mixes. In this representation, for each hour of the year in question, a representative kWh of the Swiss mix is represented by circles that have been colored differently according to the month of reference. The spectrum of variation in energy use and carbon emission can be particularly appreciated with the inset in Fig. 6, where the two months with the most differing results are depicted. While at some given time, the PEF of the Swiss mix is lower than the average one
Final energy

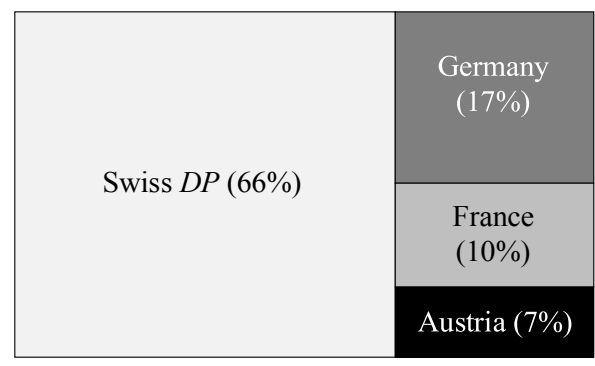

GHG emissions




cumulated over a one-year period. (DP: Domestic production). 

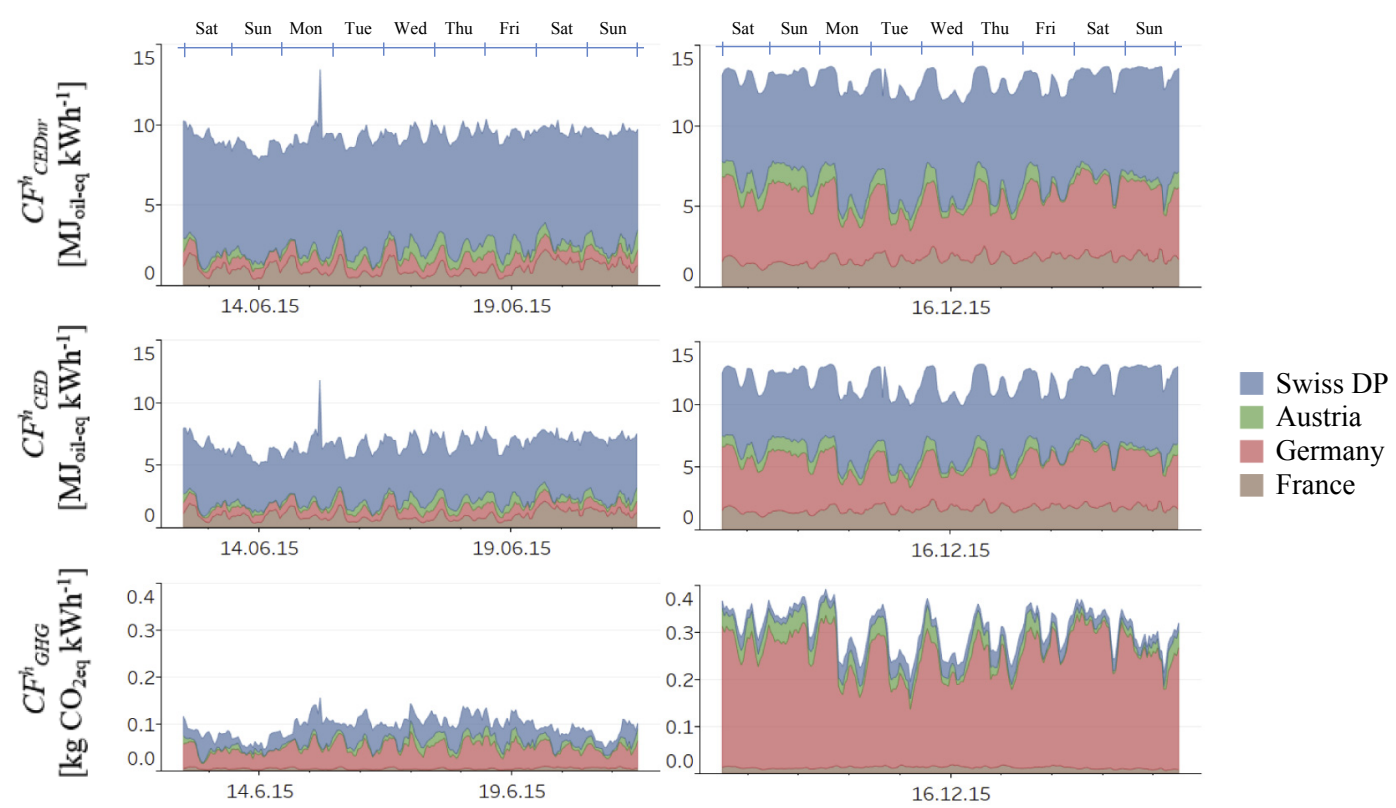

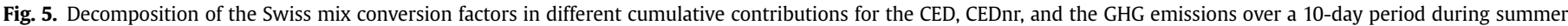
(left side), and winter (right side). In each graph, the upper curve represents the level of the Swiss mix.

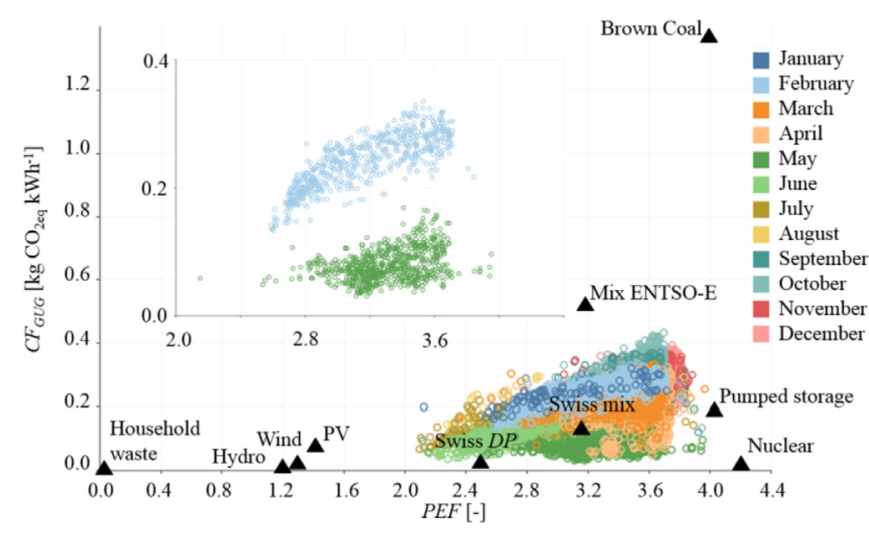

Fig. 6. Annual representation of the hourly $P E F$ and $C F_{G H G}$ associated with the Swiss mix (colored circles) and its domestic production (DP), as well as technology-specific characteristic values (both represented by black triangles) given by the KBOB database [23]. The inset contains the same data, but rescaled and only for two months.
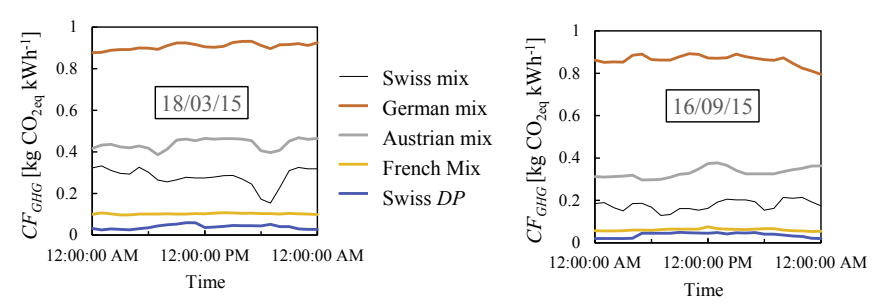

Fig. 7. Hourly GHG emission factors of the different contributors to the Swiss grid for the third Wednesday of March 2015 (left side) and the third Wednesday of September 2015 (right side).

of the Swiss domestic production, it is possible at any moment of the year to have an hourly GHG emission factor of the Swiss mix lower than the average value of its sole domestic production.

When increasing the temporal resolution in the exploration of the results, the succession of hourly conversion factors and their daily evolution are now analyzed. By looking at a portion of the dataset corresponding to a weekday in Fig. 5 , it can be seen that the different tracks of $C F_{G H G}^{h}, C F_{C E D}^{h}$, and $C F^{h}{ }_{C E D n r}$ related to the Swiss mix could be assimilated in the shape of a $\mathrm{W}$ for both winter and summer. The center/upper kink is centered at noon, and the two lower kinks appear around breakfast and dinner time. As seen in Fig. 7, in which the change of $C F_{G H G}^{h}$ is plotted daily, this W shape no longer applies during the mid-season, at least for the emission factor. The two days detailed in Fig. 7 are also reported with two vertical blue lines in Fig. 3. When ranking the different national grids by their emission factor level, the order of the different contributions remains the same for the two days presented in Fig. 7. These features generally remain the same all year long, except during the May-August period, where the Swiss domestic production $C F_{G H G}^{h}$ becomes slightly higher than the French $C F_{G H G}^{h}$.

Having a quick overview of the successive daily variation over a full-year period is possible with a heat-map visualization, as proposed in Fig. 8 (left side). In this representation, each rectangle represents a given hour (vertical axis) on a given day (horizontal axis). The hourly value of the emission factor related to the Swiss electric mix is compared with its daily average $\mu^{d}$. The obtained difference is associated with a color (see the color legend at the top of Fig. 8). By comparing the color contrast obtained on each vertical line representing each day, winter appears to be the period when the daily volatility of $C F_{G H G}^{h}$ is at its highest. The daily W-shaped pattern previously discussed, recognizable especially in winter and summer, fades away during spring. As confirmed with the electricity-generation inventories used in this study, it is also during this period that the Swiss electric mix is powered with more stable associated life-cycle GHG emissions.

The aggregation of the daily variation of $C F_{G H G}^{h}$ into a mean representative week is shown on the right side of Fig. 8. A strong homogeneity between the daily variations is observable during weekdays. The peak in variation exhibited during the lunch break smoothes out on Saturday and is inexistent on Sunday. In addition, the change from positive to negative difference between the daily and the hourly $C F_{G H G}^{h}$ appear later during weekend mornings. As a general trend, carbon intensities rise at night. 

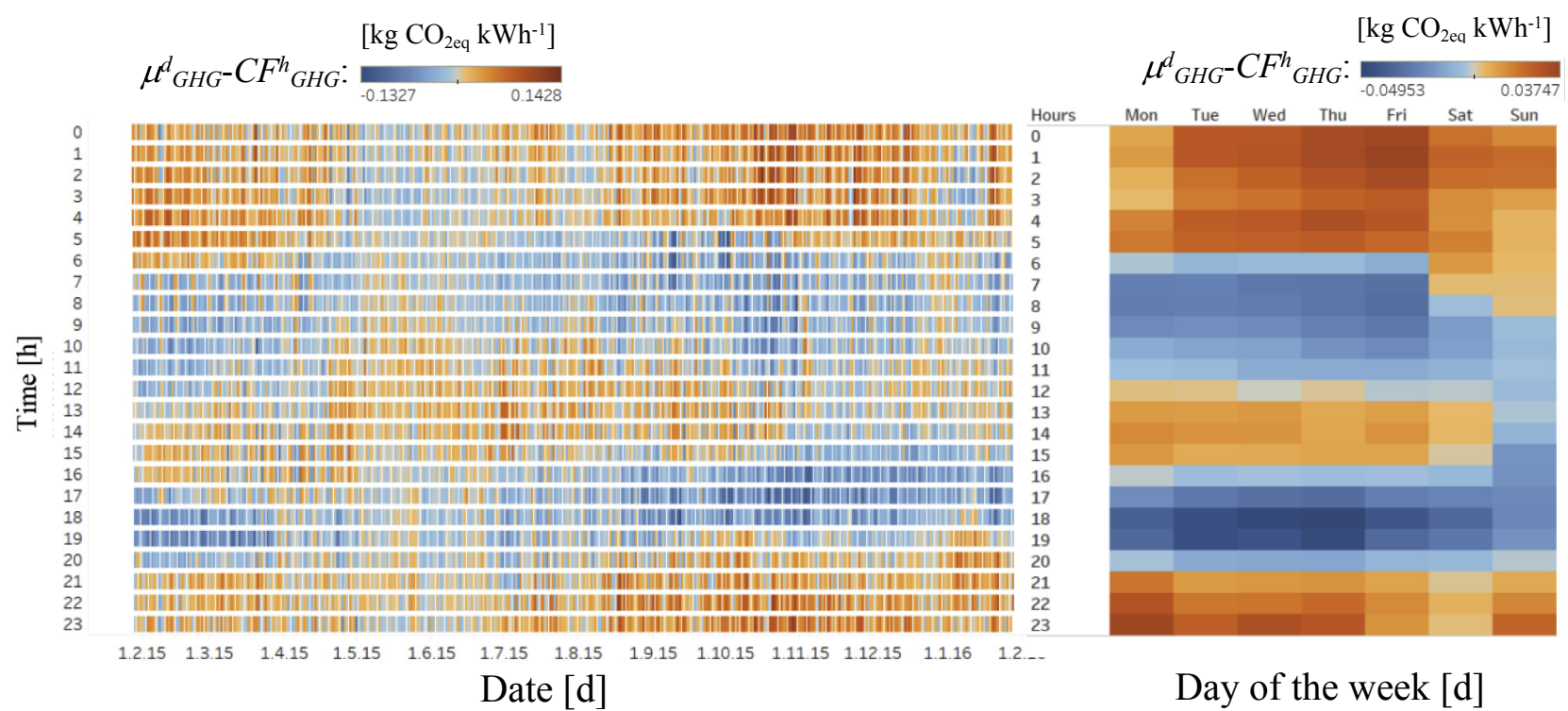

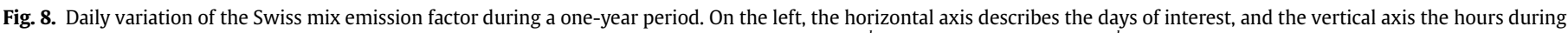

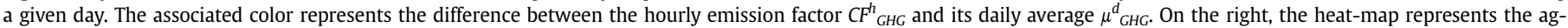
gregation of the one-year period into a mean annual week.

\section{Discussion}

As introduced in section 2, the model used in this study offers two ranges of accuracy, depending on the considered country. When determining hourly conversion factors of electricity, the highest level of accuracy is at its best for Switzerland, the main country of interest. Due to assumptions detailed in Eq. (7), some inaccuracies are introduced for the countries surrounding Switzerland. By carrying out a sensitivity analysis, we can estimate how much the values obtained for the Swiss grid are affected by the simplification made in our model regarding these surrounding countries, i. e mean annual conversion factors and mean annual amount of imported electricity.

Firstly, we investigate the impact in the variation of the amount of electricity imports. At a given time, and for a given surrounding country, the electricity imports could be different than its yearly averaged value. If this instantaneous value is half the mean average value, the corresponding national emission factor is impacted by $-6.2 \%$; $-7.7 \%$ and $+1.2 \%$ respectively for France, Austria and Germany. The change in these national emission factors would then lead to a variation of the Swiss emission factor of $-0.2 \%$. If an instantaneous amount of electricity import is twice the mean average value, the French, Austrian, and German emission factors would correspond now to respectively $+11.0 \% ;+15.5 \%$ and $+2.7 \%$ of the initial value. The change in these national emission factors would lead to a variation of the Swiss emission factor of $-0.4 \%$.

Secondly, we investigate the impact in the variation of the conversion factor of imported electricity. By a reduction of $50 \%$ of the ENTSO-E emission factor, the carbon footprints of the French, Austrian, and German mix are impacted by $-6.4 \%$; $-18.8 \%$ and $-2.1 \%$ respectively for France, Austria, and Germany. When taking into account these values for assessing the Swiss mix, the results are impacted by $-3.6 \%$. When repeating the same process with a surcharge of $50 \%$ regarding the ENTSO-E emission factor, the carbon footprints of the French, Austrian, and German mix are impacted by $6.4 \% ; 17.8 \%$ and $2.0 \%$ respectively for France, Austria, and Germany. Finally, when taking into account these values when assessing the Swiss mix, the results is impacted by $6.3 \%$.

According to this sensitivity analysis, it appears that the German grid is assessed with a much better accuracy than the French one.
This is due to the low amount of electricity imports (See Fig. 2) and to the very stable German mix (See CV factors in Tables 2-4). The least accurate assessment is the one of the Austrian grid which exhibits a high amount of electricity imports and important daily variations (See Fig. 7). It seems easier to improve the hourly CFs assessment accuracy by integrating in the surrounding countries an hourly description of electricity imports rather than expecting a better resolution of the CFs of electricity imports.

Furthermore, we propose to compare the energy-pondered mean annual carbon footprint of electricity obtained in this study with those published by official organizations (Table 5).

In order to have agreement between the different data presented in Table 5, two conditions should be simultaneously respected: an extensive electricity-generation inventory, and the technology-specific conversion factor used for both assessments, need to be the same. The results given in Table 5 shows that the French case palpably satisfies both conditions. Even if France belong to a second-class accuracy country due to the applied methodology, the strong agreement between the two assessments is reached thanks to the very low amount of electricity imports from the French grid. In both assessments, the same electricity-generation inventory is used. With regard to the technology-specific conversion factor, those used by ADEME [32] are apparently very close to those of the Swiss database KBOB [23]. For the other investigated countries, this aspect is not the case. When considering the German grid, the inventory of the German domestic electricity generation of electricity used in this study [27] represents $98.8 \%$ of the full domestic production published by the German government. On the other hand, the KBOB technology-specific emission factors are systematically of higher value than those used by the German government [31] when assessing GHG emissions related to their electricity. Fig. 9 displays these values for the more carbonintensive electricity generation technology. In the same figure, the variability range of these values are also displayed. As a result, despite the good agreement of both inventories, the use of different emission factors leads to a significant increase $(+41 \%)$ in the obtained results of emission conversion factors, compared with those published by the German government [31].

It is a bit more problematic to judge the robustness of the obtained results when dealing with a sample of data instead of the full 
Table 5

Comparison of the obtained carbon footprint with data published by official organizations.

\begin{tabular}{|c|c|c|c|c|c|}
\hline \multirow[t]{2}{*}{ Country } & \multirow{2}{*}{$\frac{\text { This study }}{\mu^{p, y}{ }_{G H G}\left[\mathrm{~kg} \mathrm{CO}_{2 \mathrm{eq}} \mathrm{kWh}^{-1}\right]}$} & \multicolumn{3}{|l|}{ Others' published data } & \multirow[t]{2}{*}{ Difference } \\
\hline & & $C F_{G H G}\left[\mathrm{~kg} \mathrm{CO}_{2 \mathrm{eq}} \mathrm{kWh}^{-1}\right]$ & Reference & Year & \\
\hline Switzerland & 0.203 & 0.139 & [23] & 2014 & $+46 \%$ \\
\hline Austria & 0.352 & 0.222 & [30] & 2013 & $+59 \%$ \\
\hline Germany & 0.860 & 0.534 & [31] & 2015 & $+41 \%$ \\
\hline France & 0.080 & 0.082 & [32] & 2014 & $-2.4 \%$ \\
\hline
\end{tabular}

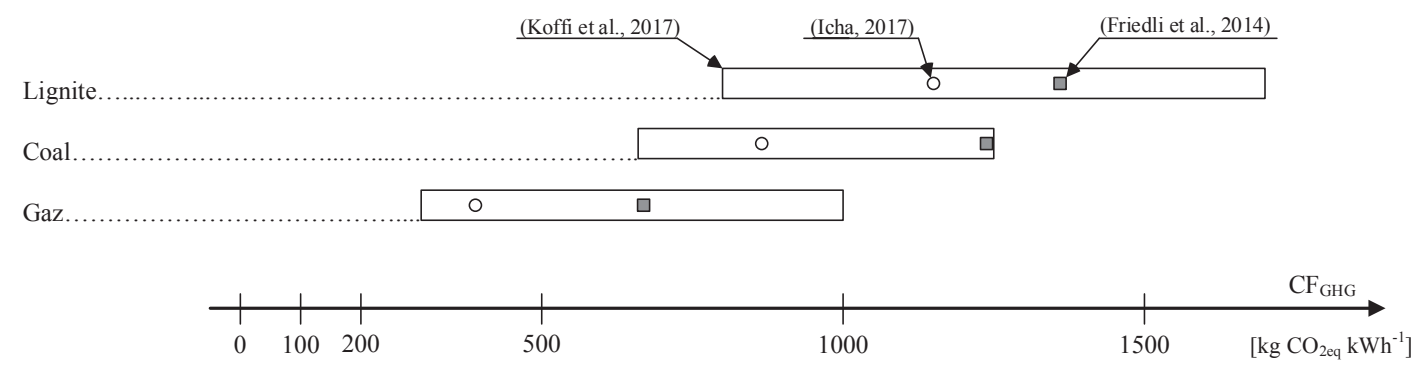

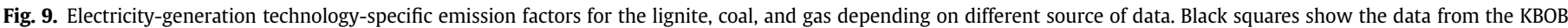
database [23] open circles shows data used by the German government [31] and the rectangular box shows the span of data from a wide literature screening [30].

amount of a given domestic production of electricity. Regarding the Swiss grid in particular, when an energy-weighted annual average based on hourly data $\mu^{p, y}{ }_{G H G}$ is assessed for the Swiss mix, and is compared with the data provided by the KBOB database [23], the proposed method with the data at disposal provides substantially higher results (see Table 5). The differences obtained between the annual assessments performed in the frame of the present study and the КВОВ database are smaller but still positive for energies $(+5.3 \%$ for CED $+8.5 \%$ for CEDnr) than for the GHG emissions.

Apart from choosing appropriate technology-specific conversion factors, another limitation of the method is the current data availability for performing accurate electricity-generation inventory and robust potential-impact assessment. Higher results obtained for the three conversion factors assessed on an hourly base could also be explained by data not reported in the electricity generation inventory. These missing data probably cause the sudden discontinuity in the Swiss production contribution appearing during the late afternoon on 15/06/2015 in Fig. 5, as well as some peaks displayed during very small periods of time (range of an hour) in the three curves depicted in Fig. 3. These discontinuities are generated by the Swiss domestic production data, but it is not clear if the cause is the lack of some data or if these features are truly relevant of the domestic production. In our case, these discontinuities affect both the mean annual values and the volatility of the Swiss mix conversion factor assessments given in Tables 2-4.

The importance of using hourly conversion factors, instead of their mean annual values, in a given country can be appreciated by the $C V$ coefficient (Tables 2-4). Smaller $C V$ indicates a low propensity to inaccuracies in the impact assessment with the mean annual conversion factor. In this context, we can see that among the different national grids investigated in this study, the German grid is the least problematic one. The gain in accuracy does not depend only on the environmental characteristics of the mix, but also on the temporal variation of energy use. To illustrate, let's go back to the GHG emissions associated with the electricity of each national mix that have been assessed with the hourly emission factor in Fig. 4. When performing the same evaluation with yearly averaged emission factors (those of Table 2) instead of an assessment performed with hourly emission factors, GHG emissions would be underestimated (for Austria: -5.8\%; for France: 5.2\%; for the Swiss production: $-4.8 \%$ ) except in Germany, where it would remain roughly the same.
But comparing the respective coefficient of variation of the conversion factor belonging to the different investigated grids (Tables 2-4) does not allow for ranking the different countries by their potential in saving energy and GHG emission mitigation, by applying strategies involving timing optimization of electricity use. Energy and emissions mitigation efficiency depend on the technology at the top the merit order, which are those that are going to adjust its production responding to a change in the electricity demand. A quantitative assessment of such optimization strategies could be made through a consequential analysis (see Refs. [33,34, but such an analysis is beyond the scope of this paper.

Stakeholders concerned with the sustainability of electric grids (e.g. grid managers, policy makers) could use the present methodology to carefully choose the origin of their electricity imports. Repeating the methodology over the years enables monitoring of decarbonization induced by energy transition policies. The current trends of big data-resulting in the increasing amount of information made available day after day-will make the proposed method highly applicable in the future. One example is the UK energy generation, which has been published by the Elexon portal [35] with a 30 min-resolution fuel mix data. Real-time pricing contracts of electricity introduced in many countries, together with increasing normative pressure concerning the guarantee of origin of electricity, are a great opportunity for extensive electricitygeneration inventory. Day-ahead energy market (see Ref. [36] could even make possible short-term forecasting of electricity conversion factors before its usage. The technical constraints for life-cycle labeling of electricity seem today very small and could be supported mainly by the holistic communication features of smart grids, where information technologies such as block chains could be implemented.

\section{Example of a footprint assessment}

In this section, we illustrate with a case study how much the accuracy of energy and emission assessments can be increased when using hourly conversion factor instead of yearly averaged value. When combining variable electricity consumption with an electric grid, constant averaged conversion factors of supply mix could cause overestimation or underestimation in assessments (see Refs. $[10,14]$. Buildings are known for having a very strong timedependent energy demand over the year. Residential and service 


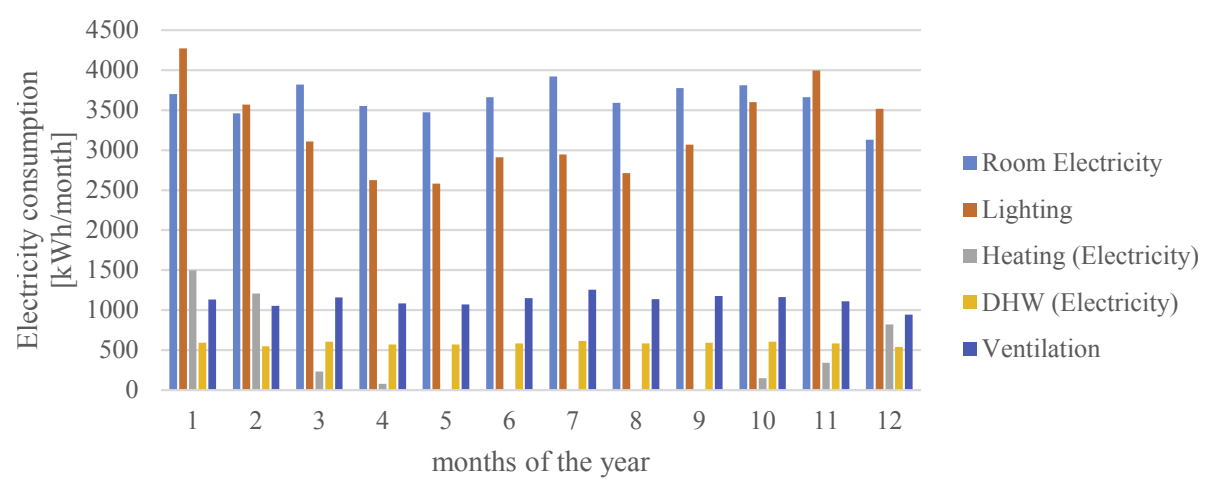

Fig. 10. Forecast of the monthly electric consumption of the given case study by end-use sectors of electricity. (DHW: domestic hot water).

sectors are responsible for approximately half of the world's energy consumption [13]. The selected case study is a building project which will be completed by 2022 in Fribourg, Switzerland. The building consists of a mix of apartments (1148 $\mathrm{m}^{2}$ ERA) and offices (2917 m² ${ }_{\text {ERA }}$ ) (ERA: energy reference area). A possible architectural layout (cuboid of $22 \times 29 \times 23 \mathrm{~m}$ ) provides the basis for an hourly energy assessment of the building (see Ref. [37] for more detailed information), performed with the energiePlus software [38]. The use of a heat pump is considered for space heating and for providing the domestic hot water $(D H W)$. Therefore, except for renewable sources (geothermal), electricity from the grid is the sole energy supply of the building. A simulation forecast of the electricity consumption by usage and by month over one year is presented in Fig. 10.

When assessing the annual GHG emissions due to the operational phase of our case study with the conventional method involving fixed yearly emission factors (Table 5), we obtain $5.43[\mathrm{~kg}$ $\mathrm{CO}_{2 \text {-eq }} \mathrm{m}^{-2}$ ERA]. This value is overestimated by $1.9 \%$ when assessed with hourly data for both the consumption and the emission factors of the electricity, which reaches $5.33\left[\mathrm{~kg} \mathrm{CO}_{2-\mathrm{eq}} \mathrm{m}^{2}\right.$ ERA $]$. This overestimation is even more important for CED $(+2.9 \%)$ and for CEDnr $(+5.0 \%)$. Implementing the same building with the same electricity demand in a country with a grid having more stable conversion factors over time would diminish the gap between the two methods of assessments. For example, if the German grid would have supplied the same building, the overestimation of the GHG emissions by the use of mean annual emission factor would be less than $0.2 \%$.

Hourly conversion factors are not yet widely available. Therefore, in order to assess operative impacts more accurately than the conventional method, mean annual conversion factors discriminated by end-use sectors were introduced in France by ADEME and EDF in 2005 [32]. When assessing the mean values of $C F_{G H G}, C F_{C E D}$, and $C F_{C E D n r}$ of the electricity by end-use sectors of our case study and its specific electricity consumption over a year, we obtain the results presented in Table 6.

Except for heating, where a substantial increase is noticed $(+18 \%)$, only a small variation between electricity emissions factors by end-use sectors and the mean annual factor are exhibited. These variations are very small compared to the ones published by ADEME [32] in France ( $+255 \%$ for heating in 2014). Unlike the values published by ADEME that are related to a large sample of buildings, the values evaluated in Table 6 concern a single case study, and are therefore not representative of the actual Swiss building stock. Variation in terms of primary energy (CED) and its non-renewable part (CEDnr) exhibits the same tendencies, but with smaller amplitudes.

\section{Conclusion}

The role of electricity in processes and products is of primary importance. Therefore, an accurate account is much needed of its potential environmental impacts, with robust life-cycle inventories and precise conversion factors. Temporal changes in electricity conversion factors need to be understood not only to more accurately assess the environmental impacts of processes and products requesting electricity, but also to implement innovative strategies towards energy or GHG emission mitigation by a timing optimization of electricity use.

In this study, temporally-resolved LCA is applied throughout a year at an hourly time step. The hourly GHG emission factor, along with the conversion factors for the cumulative energy demand and its non-renewable part-also called carbon and energy footprints, respectively-are for the first time ever assessed for the Swiss electric grid. These factors are also assessed for neighboring countries (France, Austria, and Germany), but with a lower level of accuracy. Based on the best current possibilities of data availability, the applied attributional method gives satisfactory results whenever appropriate technology-specific conversion factors are used and when a thorough electricity-generation inventory is possible (e.g. the French grid). At present, this could be a practical challenge for some countries. In this study, the Swiss domestic production has been approximated by a sample corresponding only to the part traded at the leading energy exchange in Europe. It is believed that data availability will increase in the future, enabling the assessment of dynamic conversion factors not only in retrospect-which is the

Table 6

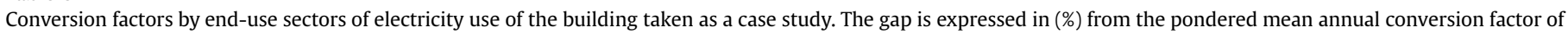
the Swiss mix to the one assessed by end-use sectors.

\begin{tabular}{|c|c|c|c|c|c|c|}
\hline & Swiss mix & Appliances & Lighting & Heating & DHW & Ventilation \\
\hline$\mu_{G H G}^{y}\left[\mathrm{~kg} \mathrm{CO}_{2 \mathrm{eq}} \mathrm{kWh}^{-1}\right]$ & 0.203 & 0.199 & 0.202 & 0.239 & 0.205 & 0.199 \\
\hline Gap [\%] & $\mathrm{N} / \mathrm{A}$ & -2.0 & -0.5 & 17.7 & 1.0 & -2.0 \\
\hline$\mu_{\text {CED }}^{y}\left[\mathrm{MJ}_{\text {oil-eq }} \mathrm{kWh}^{-1}\right]$ & 11.902 & 11.682 & 11.648 & 12.083 & 11.836 & 11.699 \\
\hline Gap [\%] & $\mathrm{N} / \mathrm{A}$ & -1.8 & -2.1 & 1.5 & -0.6 & -1.7 \\
\hline$\mu_{C E D n r}^{y}\left[\mathrm{MJ}_{\text {oil-eq }} \mathrm{kWh}^{-1}\right]$ & 10.503 & 10.187 & 10.140 & 10.874 & 10.422 & 10.214 \\
\hline Gap [\%] & $\mathrm{N} / \mathrm{A}$ & -3.0 & -3.5 & 3.5 & 0.8 & -2.8 \\
\hline
\end{tabular}


case at present-but also in real-time and in forecast.

Time evolution of the investigated conversion factors have been explored with various visualization techniques at different timescales (daily, weekly, seasonally, and annually), and the volatility of the obtained results have been quantified by a variation coefficient $(C V)$. By comparing their $C V$ indicators, the different national grids have been ranked according to the potential inaccuracies when energies and GHG emissions are assessed on the base of mean annual conversion factors instead of hourly ones; the Swiss grid is ranked number one. Although the present study deals with a limited number of indicators, the same methodology can be used for more extensive sets of environmental indicators. Repeating the methodology through successive years enables energy analysts and policy makers to quantitatively monitor energy transition. Massive decarbonization of electricity mixes should be possible, by implementing timing optimization of electricity use or by strategically selecting the origin of electricity imports. In Switzerland, for example, $35 \%$ of the electricity is imported. This amount is responsible for $87 \%$ of the GHG emissions related to the Swiss electricity mix, from which $70 \%$ are induced by German imports only.

The relevance of using dynamic conversion factors for energy and emission assessments (instead of mean annual values) has been demonstrated through a case study consisting of an energyefficient building that hosts offices and dwellings. Based on the obtained data applied to the case study, emission factors discriminated by end-use sectors indicate a possible opportunity in given countries for more accurately assessing GHG emissions in buildings, until environmental-footprint labelling of electricity becomes widely available.

\section{Acknowledgement}

The work presented in this paper has been funded by the State of Fribourg (message du Conseil d'Etat au Grand Conseil 2014-DEE22) and EPFL. We thank Denis Lalanne for valuable inputs as well as Endrit Hoxha and Stefano Cozza for constructive discussions.

\section{References}

[1] Alderson H, Cranston GR, Hammond GP. Carbon and environmental footprinting of low carbon UK electricity futures to 2050. Energy 2012;48(1): 96-107.

[2] Miller L, Carriveau R. Balancing the carbon and water footprints of the Ontario energy mix. Energy 2017:125:562-8.

[3] Shaikh MA, Kucukvar M, Onat NC, Kirkil G. A framework for water and carbon footprint analysis of national electricity production scenarios. Energy 2017;139:406-21.

[4] European Commission. Buildings - energy [WWW Document]. 2016. Energy. URL: goo.gl/dQW4ch. [Accessed 15 February 2018].

[5] Swiss society of engineers and architects. Bulletin SIA 2040: efficiency path for energy. 2017. p. 1-27.

[6] U.S. Green Building Council. LEED certifications. 2018. Available: https://new. usgbc.org/leed. [Accessed 15 February 2018].

[7] Alliance HQE-GBC. HQE certifications. 2018. Available: http://www.hqegbc org/buildings/certifications/. [Accessed 15 February 2018].

[8] Building Research Establishment. BREEAM certifications. 2018. Available: https://www.breeam.com/. [Accessed 15 February 2018].

[9] Dixit MK, Fernández-Solís JL, Lavy S, Culp CH. Need for an embodied energy measurement protocol for buildings: a review paper. Renew Sustain Energy Rev 2012;16(6):3730-43.

[10] Kopsakangas-Savolainen M, Mattinen MK, Manninen K, Nissinen A. Hourlybased greenhouse gas emissions of electricity-cases demonstrating possibilities for households and companies to decrease their emissions. J Clean Prod 2015; 153:384-96.

[11] Messagie M, Mertens J, Oliveira L, Rangaraju S, Sanfelix J, Coosemans T, Van Mielo J, Macharis C. The hourly life cycle carbon footprint of electricity generation in Belgium, bringing a temporal resolution in life cycle assessment. Appl Energy 2014;134:469-76.

[12] European Commission. ILCD international reference life cycle data system (ILCD) handbook - general guide for life cycle assessment - detailed guidance. Luxembourg: European Commission, Joint Research Centre, Institute for
Environment and Sustainability; 2010. p. 1-417.

13] Roux C, Schalbart P, Peuportier B. Accounting for temporal variation of elec tricity production and consumption in the LCA of an energy-efficient house. J Clean Prod 2015;113:532-40.

[14] Vuarnoz D, Jusselme T, Cozza S, Rey E, Andersen M. Studying the dynamic relationship between energy supply carbon content and building energy demand. In: Proceedings PLEA 2016, Los Angeles, USA; 2016.

[15] Roux C, Schalbart P, Assoumou E, Peuportier B. Integrating climate change and energy mix scenarios in LCA of buildings and districts. Appl Energy 2016;184: 619-29.

[16] Kristinsdóttir AR, Stoll P, Nilsson A, Brandt N. Description of climate impact calculation methods of the CO2e signal for the Active house project. KTH Royal Institute of Technology; 2013. p. 1-23.

[17] Soimakallio S, Kiviluoma J, Saikku L. The complexity and challenges of determining GHG (greenhouse gas) emissions from grid electricity consumption and conservation in LCA (life cycle assessment)-a methodological review. Energy 2011;36(12):6705-13.

[18] Itten R, Frischknecht R, Stucki M. Life cycle inventories of electricity mixes and grid, Tech. Rep. Version 1.3. ESU Services Ltd. Switzerland: On behalf of the Paul Scherrer Institute (PSI); 2014. p. 1-221.

[19] Spork C, Chavez A, Gabarell Durany X, Patel M, Villalba Mendez G. Increasing precision in greenhouse gas accounting using real-time emission factors, a case study of electricity in Spain. J Ind Ecol 2014;19:380-90.

[20] Jochem E, Andersson G, Favrat D, Gutscher H, Hungerbühler K, von Rohr PR, Spreng D, Wokaun A, Zimmermann M. Step towards a sustainable development: a white book for R\&D of energy-efficient technologies. Novatlantis. 2004. p. 1-66.

[21] ISO 14040. Environmental management - life cycle assessment - principles and framework. Geneva, Switzerland: International Organization for Standardization; 2006a.

[22] ISO 14044. Environmental management - life cycle assessment - requirements and guidelines. Geneva, Switzerland: International Organization for Standardization; 2006b.

[23] Friedli R, Jauslin M, Meile O, Affentranger C, Steiner V, Faber C, Nufer R, Egli N, Puder A, Dubas D, Waeber R, Lalive A, Pöll M, Pyroth C, Rhyner D, Buchmüller A, Coppey C, Henking T, Keller C. KBOB 2009/1:2014. KBOB, Office fédéral des constructions et de la logistique. 2014. Berne, Switzerland. Available: http://urlz.fr/6u93. [Accessed 15 February 2018].

[24] Frischknecht R, Jungbluth N, Althaus HJ, Doka G, Heck T, Hellweg S, Hishier R, Nemecek T, Rebotzer G, Spielmann M, Wernet G. Overview and methodology. In: Ecoinvent report, 1. Dübendorf, Switzerland: Swiss center for life cycle inventories; 2007. p. 1-68.

[25] IPCC. Climate change 2013: the physical science basis. Cambridge, United Kingdom and New York, NY, USA: Contribution of Working Group I to the Fifth Assessment Report of the Intergovernmental Panel on Climate Change Cambridge University Press; 2013. p. 1-1535.

[26] OFEN (Office Fédérale de l'Energie). Electricity supply, html document. 2016 Available, http://www.bfe.admin.ch/themen/00612/?lang=en. [Accessed 15 February 2018].

[27] EEX (European Energy Exchange). EEX transparency platform. 2016. Available, https://www.eex-transparency.com/. [Accessed 15 February 2018].

[28] RTE (Réseau de Transport de l'Electricité). Production d'électricité par filière. Database; 2016. Available: http://www.rte-france.com/fr/eco2mix/eco2mix. [Accessed 15 February 2018].

[29] Swissgrid. Aperçu énergétique suisse 2015 \& 2016. Excell Worksheets; 2016. Available: https://www.swissgrid.ch/fr/home/operation/grid-data/generation. html. [Accessed 15 February 2018].

[30] Koffi B, Cerutti AK, Duer M, Iancu A, Kona A, Janssens-Maenhour G. Covenant of mayors for climate and energy: default emission factors for local emission inventories. Luxembourg: European union; 2017. p. 1-53.

[31] Icha P. Entwicklung der spezifischen Kohlendioxid-Emissionen des deutschen Strommix in den Jahren 1990-2016. Umweltbundesamt. Dessau-Roßlau 2017:1-27.

[32] ADEME. Base Carbone V11.0, documentation des facteurs d'émission de la Base Carbone. 2016. p. 1-280. Available: http://urlz.fr/6u90. [Accessed 15 February 2018]

[33] Rawlings J, Coker P, Doak J, Burfoot B. Do smart grids offer a new incentive for SME carbon reduction? Sustain Cities Soc 2014;10:245-50.

[34] Lau ET, Yang Q, Taylor GA, Forbes AB, Wright PS, Livina VN. Optimisation of costs and carbon savings in relation to the economic dispatch problem as associated with power system operation. Elec Power Syst Res 2016;140: 173-83.

[35] Elexon portal. 2018. Available: https://www.elexonportal.co.uk. [Accessed 15 February 2018]

[36] Perković L, Mikulčić H, Pavlinek L, Wang X, Vujanović M, Tan H, Baleta J, Duić N. Coupling of cleaner production with a day-ahead electricity market: a hypothetical case study. J Clean Prod 2016;143:1011-20.

[37] Vuarnoz D, Cozza S, Jusselme T, Magnin G, Schafer T, Couty P, Niederhauser EL. Integrating hourly life-cycle energy and carbon emissions of energy supply in buildings. 2018. submitted for publication.

[38] Crawley DB, Lawrie LK, Winkelmann FC, Buhl WF, Huang YJ, Pedersen CO Strand RK, Liesen RJ, Fisher DE, Witte MJ, Glazer J. EnergyPlus: creating a newgeneration building energy simulation program. Energy Build 2001;33(4): 319-31. 